\title{
Research on the Communication and Marketing Strategy of Zhanjiang's City Brand
}

\author{
Weidong Lai ${ }^{1,2}$, Zhaoxi Deng ${ }^{3}$ \\ ${ }^{1}$ School of Business, Lingnan Normal University, Zhanjiang, China \\ ${ }^{2}$ Guangdong Coastal Economic Belt Development Research Center, Zhanjiang, China \\ ${ }^{3}$ Finance Department, Zhanjiang Preschool Education College, Zhanjiang, China
}

Email address:

natureeast@139.com (Weidong Lai),366861668@qq.com (Zhaoxi Deng)

\section{To cite this article:}

Weidong Lai, Zhaoxi Deng. Research on the Communication and Marketing Strategy of Zhanjiang's City Brand. International Journal of Management and Fuzzy Systems. Vol. 6, No. 3, 2020, pp. 47-52. doi: 10.11648/j.ijmfs.20200603.11

Received: September 29, 2020; Accepted: October 12, 2020; Published: October 17, 2020

\begin{abstract}
City image dissemination is to use the city as a foothold to spread the specific image of the city. City image dissemination is a social management activity and process to enhance the city's influence and reputation. Currently, city resources are limited and competition among cities is becoming increasingly fierce. Using the principles of branding to brand a city will help to enhance the breadth and depth of the effect of city image dissemination. Through the dissemination of city brands, highlight the characteristics of the city, improve the business environment, attract talents, and seize development opportunities. How to do a good job in spreading the city brand of Zhanjiang and increase the popularity of Zhanjiang is based on the research of this research institute. This article takes Zhanjiang as the research object, and finds three main factors that influence the spread of Zhanjiang's city brand image through big data and social networks: First, there are many and mixed images, resulting in fuzzy perception. Second, the lack of communication methods and channels has resulted in limited information acquisition. The third is the low degree of brand image recognition and low stakeholder attention. These factors restrict the shaping and dissemination of city brands. Therefore, this article attempts to reposition the city image of Zhanjiang and build a city brand with Zhanjiang characteristics. Promote Zhanjiang's reputation through the spread and marketing of Zhanjiang city brands, promote the improvement of the city's comprehensive competitiveness, and promote Zhanjiang to better build an important development pole for a modern coastal economic belt.
\end{abstract}

Keywords: Zhanjiang, City Brand, Communication and Marketing Strategy

\section{Introduction}

A city is a huge cultural system of social interaction, a collection of civilizations and cultures produced by social network interaction. The emergence of a city's image comes more from people's social activities. In the era of traditional mass media, the emergence of city images is affected by the combined effects of mass media and interpersonal communication. As the city's soft power, its rational development and utilization can create a good public opinion environment and development space for the city, and help promote the city's comprehensive competitiveness. City image communication is two-way communication with brand thinking. Arouse the awareness of the city image of city residents internally, form a huge synergy of city development, enhance the radiation and influence of the city externally, and obtain a more attractive city impression.

Zhanjiang is one of the first fulcrum cities for maritime cooperation under the "Belt and Road" initiative, and is the central city of Beibu Bay. Zhanjiang has successively won the honorary titles of "Sanitary City of Guangdong Province", "Civilized City of Guangdong Province", "Excellent Tourist City in China" and "National Garden City". In 2010, Zhanjiang was awarded the title of "China's Seafood and Gourmet Capital", and won the "China's Prawn Capital" and "China's Top Ten Green Cities". In 2015, Zhanjiang was named "National Sanitary City". In 2019, Zhanjiang was selected as one of the "Top 50 Cities with the Most Investment Potential in China in 2018". How to do a good job in spreading the city brand of Zhanjiang and increase the popularity of Zhanjiang is based on the research of this 
research institute. This article analyzes the current status of city brand communication from three aspects: Zhanjiang city image positioning, city image dissemination audience, and city image dissemination path. Based on the above analysis of the current situation, measures such as optimizing the brand positioning of Zhanjiang city, integrating multiple communication channels, accurately segmenting the communication audience, and improving the communication supervision mechanism are proposed. Through the discussion, It may help Zhanjiang city brand building and provide some references for brand positioning in other cities.

\section{Research Status}

In the existing research, scholars have used marketing, management, and informatics to discuss city brand building, city brand communication and marketing issues. The research results are fruitful, which can be roughly divided into the following two research topics:

\subsection{Research on City Communication and Marketing Subjects}

The research group represented by Professor Yang Kaizhong has conducted pioneering research on city marketing. Professor Yang Kaizhong believes that city marketing is the use of marketing theories and methods to manage cities. It is based on the principle of market demand orientation and market competition drive [1]. Guo Xiaoxing analyzed from the perspective of diversified governance that the government should focus on the platform construction of other entities' participation and grasp the direction in the new environment. The author believes that city marketing is different from the traditional marketing theory. The main body of city marketing should be pluralistic, and the government is the leading role of the pluralistic main body [2]. Tan Yufei and others focused on various short video platforms, through the comprehensive use of multidimensional symbols, to spread the splicing of fragmented micro-themes, forming a "puzzle-like" city image communication framework. It subverts and reconstructs the traditional city image with a macro vision, a local perspective, and a communication path and structure that emphasize unity and holistic cognition [3]. Sun $\mathrm{Xu}$ and others believe that in terms of communication methods, integrated marketing communication strategies should be adhered to promote city tourism brands. In the application of specific strategies, a variety of approaches should be used comprehensively to implement integrated marketing communication, and focus on the promotion of city tourism image communication performance [4]. Vodopivec B and others analyzed the relationship between Mexico City's city development, cultural and political process, and city image. It focuses on the impact of city reorganization under neoliberal policies and the rise of symbolic economy on disadvantaged areas [5]. Filomena $\mathrm{G}$ et al. described how individuals perceive and recall characteristics in city spaces. The most unique elements in the city image-classified by paths, nodes, edges, regions and landmarks to shape the individual's psychological performance of the city [6].

\subsection{Research on the Evaluation of Influential Factors in Urban Communication and Marketing}

Dr. Liu Yanping's research is the most comprehensive and deepest domestic city marketing strategy at present, enriching my country's city marketing theory from a quantitative perspective. Liu Yanping published "City Marketing Strategy" [7]. In 2009, the City Marketing Index was proposed to solve the problem of city marketing development or performance evaluation [8]. Huang Heshui et al. used 9 221607 online news headlines in 37 cities from 2008 to 2017 as basic data to conduct text mining on city news big data, and build a city fashion index to quantify fashion image [9]. Ma Chao et al. mapped the concept of user portraits to the city environment and proposed the construction path of city data portraits. Combining related research on smart cities and city competitiveness, construct a faceted model of city data portraits, and conduct a time-space perspective [10]. Du Zhitao and others proposed an city portrait application system composed of three dimensions of "resources-domainrealization", revealing the application process of city portraits in the refined city governance. It is a process of forwardlooking foresight, scientific decision-making, precise governance, and future-oriented city transformation through the integration of various functional aspects and departmental resources of the city with data as the core [11].

\subsection{Research on the City Brand}

Li Chengxun has a deep insight into city brand positioning, and extracts the seven elements of city brand formation and the five principles of city brand positioning [12]. Ni Pengfei et al. elaborated on the urban brand marketing theory and brand marketing strategy, and elaborated on the branding strategies such as urban business brands, urban tourism brands, urban livable brands, and urban origin brands [13]. Ji Chunli and others adopted the brand concept map method, selected Macau as a case, and used 103 Macau residents as research samples to construct a brand concept map of "Macao", which visually revealed the network structure of local residents' perception of the brand image of "Macao" [14]. Rezvanpour $\mathrm{N}$ et al. studied the important factors and key indicators of city brand space from city design [15]. Bonenberg A et al. believed that when the competition among cities attracts residents and enterprises, it is beneficial to build the image of the city through proper city branding. The author proposes a new city assessment method to define an important but difficult to capture feature-"the city empathy method" [16].

Existing domestic and foreign scholars have defined the related concepts of city marketing, city image and city brand. In addition, scholars clarified the basic content of city marketing and also provided strategic ideas for city marketing. These theories provide systematic thinking methods and guiding principles for city managers to carry out 
business activities. Domestic scholars' research on city marketing began in the early 20th century, in an era of rapid urban development in my country. The scholars have positioned the government's leading functions and the role of other stakeholders, and put forward some thoughts on the problems in the marketing process of our cities. Through the analysis of a large number of domestic and foreign city marketing cases, the current situation of city marketing in my country is analyzed from the perspective of quantitative analysis, which provides a quantitative standard that can be referred to in improving the international competition of Chinese cities. But there are also some shortcomings, and the quantitative analysis and empirical analysis are not sufficient. Especially in the context of big data, there are not many researches on city brand communication and marketing from online and offline channels.

Based on the full analysis of city branding and positioning, city communication and marketing and other theories, this article attempts to start from the Internet and big data to study how cities can solve online and offline multi-channel city branding and communication marketing strategies.

\section{Current Status of Zhanjiang's City Brand Image}

This article mainly analyzes the status quo of Zhanjiang's city brand from three aspects: Zhanjiang's city image positioning, city image dissemination audience, and city image communication path.

\subsection{Zhanjiang's City Image Positioning}

City image positioning is the foundation of city image communication. Only through scientific and systematic overall analysis and evaluation, can we better find the key points and entry points of Zhanjiang city image positioning, and better find the difference between Zhanjiang city resources and others. The sum of the material and cultural resources of the city that can produce a good cognitive impression in the minds of the dissemination audiences, so as to obtain the city image positioning of Zhanjiang that the dissemination audiences expect.

Zhanjiang has the famous eight scenic spots: East Island, Huguangyan, Sea promenade, Jinqiao Park, Pazhou Ancient Rhyme-Weizhou Island, South Asian Tropical Botanical Garden, Nansan Island, Zhanjiang Port and so on. Blue sky, white clouds, blue sea, sail shadows, green trees, red flowers... This is the synonym of Zhanjiang. Zhanjiang is located in the seaport city of Leizhou Peninsula at the southernmost tip of the mainland of the motherland. It has always been known for its beautiful environment and unique tourism resources. In addition, Zhanjiang has a rich cultural history and a long history. Its Leizhou culture is one of the four major ethnic cultures in Guangdong and one of the main cultures of Zhanjiang. The national intangible cultural heritage includes: traditional dance Zhanjiang people's dragon dance, Suixi waking lion, Zhanjiang Nuo Dance, traditional art Leizhou stone dog, folk customs Wuchuan floating color, folk literature Leizhou song, traditional drama Leiju, traditional drama Wuchuan Cantonese opera southern art. Folk customs are also very distinctive and deeply loved by people. Zhanjiang has won public recognition and won many honorary titles for its high-quality natural landscape and human history. In different periods, Zhanjiang has different image positioning, such as "Civilized City of Guangdong Province", "Charming City with Chinese Characteristics", "Excellent Tourist City in China", "National Garden City", "City of Seafood ", etc. With the development of the "Belt and Road", Zhanjiang has become a sub-central city in Guangdong Province, a central city in the western Guangdong and Beibu Gulf city clusters, and the first batch of "Belt and Road" maritime cooperation pivot cities.

\subsection{City Image Dissemination Audience}

City image positioning compares the city to a specific brand for communication positioning. From the perspective of city dissemination audiences' expectations of the city, analyze the audience's perception of Zhanjiang's image of the city. According to the development goals of the city's image, the city's stakeholders are divided into the following three types: city residents (the existing and potential people living in the city), city investors (the capital operation in the city, including both funds and Individual human capital investment), and city tourists (use the city as a place for recreation and entertainment and the city provides products and services for it). Through the analysis of stakeholders in the process of city image communication, we found that city residents do not have a high degree of recognition of Zhanjiang's brand image, which is related to their living habits and degree of numbness. City investors have the highest recognition of Zhanjiang's brand image, so they are more willing to invest in the city of Zhanjiang. However, city tourists don't know much about Zhanjiang. They learn about Zhanjiang more through the Internet and other media. The difference between their expectations and actual values due to their personal perceptions is also different, which is very important to the brand image of Zhanjiang. The degree of recognition is different.

\subsection{City Image Communication Path}

With the continuous development of information technology and the advent of the new media era, there are more choices in the path of city image transmission. However, the current domestic city image communication methods and channels still have certain shortcomings, which are mainly manifested in the excessive dependence of city managers on traditional media, such as television, film, radio, newspapers, etc., and insufficient control of the laws of new media communication. City image communication has completely entered the all-media era. It is precisely because of the imperfect communication methods and channels that the dissemination audiences have limitations in obtaining city information. This is not conducive to the communication 
audience's true understanding of the city's brand characteristics, and may lead to a decrease in the satisfaction of the dissemination audience.

This shows that the current status of Zhanjiang's city brand mainly has the following surface:

1). There are many and mixed images, resulting in fuzzy cognition. Zhanjiang's brand positioning is not specific enough. The characteristics are not outstanding enough. The image is scattered and not focused, and the communication effect is poor. The audience's perception of Zhanjiang's city image is rather vague. Accurate positioning and raising public awareness are currently problems that need to be resolved.

2). The lack of communication methods and channels has resulted in limited information acquisition. The communication media is relatively traditional, the publicity method is relatively single, and the media integration is low and lacks diversified vitality. In addition, in the communication process, the dissemination caliber is not uniform. The continuous dissemination has not been achieved, so that the dissemination audience cannot judge the effectiveness of the information. The dissemination effect cannot be effectively reflected and fed back. There is an urgent need to introduce new media.

3 ). The brand image recognition is not high, and the interest of stakeholders is low. The degree of attention of a city depends on its development and its characteristics. Zhanjiang has developed rapidly in recent years. Taking advantage of the "Belt and Road" initiative, Zhanjiang has become one of the first batch of "Belt and Road" maritime cooperation pivot cities. How to take advantage of Zhanjiang's rapid development boom and combine Zhanjiang's characteristic natural resources and human history to bring "hot search" to Zhanjiang is a problem that we urgently need to solve. Increasing the attention of the dissemination audience is conducive to the effective communication of Zhanjiang city brand.

\section{The Communication Strategy of Zhanjiang's City Brand}

\subsection{Optimize the Brand Positioning of Zhanjiang City}

The first step in city branding is to accurately position the city. The positioning of a city must not only conform to the strategic requirements of national development, but also cannot ignore its own advantages and characteristics

"Bridgehead". Zhanjiang is positioned by the country as a strategic fulcrum city for maritime cooperation in the national "One Belt One Road", a National Marine Economic Innovation and Development Demonstration City, a national comprehensive transportation hub, and a sub-central city in Guangdong Province. It is a Bridgehead which connect between the Guangdong-Hong Kong-Macao Greater Bay Area and the South China Sea Free Trade Zone. Zhanjiang is located at the intersection of the Guangdong-Hong KongMacao Greater Bay Area, the Hainan International Tourism
Island Pilot Zone, and the Beibu Gulf City Group and other national-level regional development centers, which is conducive to promoting Zhanjiang City to better "create an important development pole for a modern coastal economic belt." "Bridgehead" is the representative of Zhanjiang.

"Charming City". Zhanjiang is rich in tourism resources. As of the end of 2018, Zhanjiang had 70 tourist attractions and 16 tourist attractions above A-level. Among them, 5 are 4A-level scenic spots, 7 are $3 \mathrm{~A}-$-level scenic spots, and 4 are 2A-level scenic spots. In addition, Zhanjiang has a rich and long history of humanities. Zhanjiang People's Dragon Dance, Suixi Lion Dance, Folklore Wuchuan Floating Color, Folk Literature Leizhou Songs, Traditional Drama Leiju, etc. have been deeply rooted in the hearts of the people. Zhanjiang attracts people from inside and outside the province with its high-quality natural resources and rich cultural history and culture. "Charming City" deserves its name.

"The City of Seafood". In 2017,"Charming Chinatown", the 12th food in Zhanjiang detonated the audience. " In January, Pomfret is very tender; in February, Oyster is fat; in March, the lobster is fat and strong; in April, the squid is sweet; in May, the sea bream is really delicious; in June, Ling is delicious too; in July, the abalone is fat; in August, grouper is precious; in September, butter crab is the best; in October, Spanish mackerel is fragrant; in November, eel is very good; in December, sandworm is the most plump" has deep into people's hearts. Zhanjiang people can make use of local highquality ingredients to make a variety of dishes suitable for guests from all directions, and to operate in good faith, clearly priced, and fair prices to attract more tourists to taste. "The City of Seafood" lives up to its reputation.

\subsection{Integrate Multiple Communication Channels}

With the advent of the new media era, new media relying on Internet technology occupy an increasingly important position in the public's information acquisition and communication. New media has been integrated into the public's daily life and changed people's lifestyles. For the image of the city Communication provides a new platform. In the era of new media, only by establishing an all-media three-dimensional communication mode that combines traditional media and new media [17], the city image communication can be more efficient. Therefore, after clarifying the positioning of the city's brand, all communication resources should be integrated. While continuing to use traditional media, such as TV, movies, radio, and newspapers, we must also actively integrate with the times and adopt new media communication methods, such as forums, blogs, Weibo, WeChat, and live broadcasts. Let everyone be a communicator, so that the scope of communication is wider and the communication effect is better.

\subsection{Accurately Segment the Dissemination Audience}

The dissemination audience of the city image is mainly divided into the internal public and the external public. In the process of city image dissemination, the main body of dissemination transmits city-related information to the 
dissemination audience through mass media. Through brain processing and a series of mental activities, the dissemination audience forms the imagination, intuition, evaluation, judgment, understanding and knowledge of the city. Therefore, before disseminating information, the dissemination audience should be accurately segmented, and then according to different audiences, different dissemination methods and different dissemination contents should be used to ensure that the dissemination audience can receive the information they need. Achieve accurate communication. The public in the city is mainly city residents, who are already familiar with the city of Zhanjiang. Therefore, they pay more attention to the latest hot issues in Zhanjiang, and they obtain information through TV, newspapers, and related Zhanjiang official accounts. The public outside the city includes city investors and city tourists. City investors pay attention to Zhanjiang's natural resources, social resources, and the latest policies, etc. They obtain information through the Internet, magazines, and advertisements. City tourists pay attention to Zhanjiang's scenic spots, humanities, transportation, consumption, etc., and they use more relevant travel apps, ticketing apps, post bars, and related websites to collect information. Through precise segmentation of communication audiences, precise communication is achieved and the effective diffusion of Zhanjiang city brand effect is realized.

\subsection{Improve the Communication Supervision Mechanism}

The diversification of communication channels not only brings benefits to the communication of city brands, but also brings certain risks. Fast spreading speed and wide spreading coverage may also cause uncontrollable online public opinion. Therefore, it is necessary to formulate a communication supervision mechanism, including real-time management of communication content, communication channels, disseminators, dissemination audiences, dissemination results, etc., to avoid major "dissemination accidents" and reduce the impact of online public opinion. In addition, it is necessary to open a feedback channel so that the communicator and the audience can respond to the problem in a timely manner, and the relevant departments can solve the problem in time.

\section{Summary}

With the development of society, city management has become more and more standardized. City brand marketing has gradually developed into the main direction of city management. The marketing concept of city branding has been generally accepted and recognized by city managers and the general public. However, many cities' brand building has fallen into the misunderstanding of "image project", and various logos and slogans have emerged one after another. These misunderstandings are more due to the failure to properly position the city's brand, the failure to distinguish between the audiences of the city's image dissemination, and the failure to plan the path of city image dissemination.
Therefore, to avoid misunderstandings and get out of the vicious circle, you must use professional brand theories and dissemination methods. By optimizing the positioning of the city's brand image, accurately subdividing the target communication audience, combining traditional media and new media, and doing accurate communication. In addition, supervision and control of dissemination should be carried out to ensure a harmonious and orderly communication environment. As the city's soft power, city image's rational development and utilization can create a good public opinion environment and development space for the city, and help promote the improvement of the city's comprehensive competitiveness.

\section{References}

[1] Yang Kaizhong. Marketing places like a marketing company [J]. Leadership Decision Information, 2001 (36): 13.

[2] Guo Xiaoxing. Research on the main body of city marketing [J]. Productivity Research, 2010 (09): 94-95.

[3] Tan Yufei, Liu Hongmei. The construction of city image by short video puzzle communication from the personal perspective [J]. Contemporary Communication, 2019 (01): 9699.

[4] Sun $\mathrm{Xu}, \mathrm{Wu}$ Yun. The concept, path and strategy of city tourism image communication in an all-media context $[\mathrm{J}]$. Media, 2018 (12): 75-78.

[5] Vodopivec B, Dürr E. Barrio Bravo Transformed: Tourism, Cultural Politics, and Image Making in Mexico City [J]. The Journal of Latin American and Caribbean Anthropology, 2019, 24 (2): 313-330.

[6] Filomena G, Verstegen J A, Manley E. A computational approach to 'The Image of the City' [J]. Cities, 2019, 89: 1425 .

[7] Liu Yanping. City marketing strategy [M]. Beijing: Renmin University of China Press, 2005.

[8] Liu Yanping. City identification and brand positioning [J]. International Public Relations, 2009 (05): 47-48.

[9] Huang Heshui, Peng Lixia. Research on Chinese City Fashion Image Based on News Big Data [J]. Journal of Xiamen University (Philosophy and Social Sciences Edition), 2019 (04): 131-140.

[10] Ma Chao, Li Gang. City data portrait construction based on city big data [J]. Modern Information, 2019, 39 (08): 3-9.

[11] Du Zhitao, Li Gang. City portraits for refined governance: components and application systems [J]. Library, Information, and Knowledge, 2019 (04): 43-51.

[12] Li Chengxun. Preliminary Study on City Brand Positioning [J]. Market Economy Research, 2003 (06): 8-10+1.

[13] Ni Pengfei. China City Competitiveness Report NO. 5 [M]. Beijing: Social Sciences Academic Press, 2007.

[14] Ji Chunli, Zeng Zhonglu. Urban residents' Perception of tourist City brand image: Based on brand concept map method [J]. Tourism science, 2017, 31 (04): 64-78. 
[15] Rezvanpour N, Bayat A. Determining effective urban design factors within the branding strategy due to brand city spaces and evaluating city spaces by comparing them to the presented factors. A case study of ChaharBagh Avn, Isfahan, Iran [J]. Energy Procedia, 2017, 115: 6-17.

[16] Bonenberg A. Place Brand-Building. Urban Empathy as an
Evaluation Method [M]//Universal Access in HumanComputer Interaction. Methods, Techniques, and Best Practices. 2016.

[17] Chen Li. Guangzhou city image optimization strategy from the perspective of brand communication [D]. 